\title{
Patentes e Sistemas Financeiros: um estudo exploratório para o Brasil ${ }^{*}$
}

\author{
Marco Crocco
}

Anderson Tadeu Cavalcante

Matheus Lage Alves de Brito

Eduardo da Motta e Albuquerque

CEDEPLAR-Universidade Federal de Minas Gerais

\section{Resumo}

O presente artigo analisa as relações existentes entre patentes e variáveis bancárias. Sua grande inovação está no uso de dados municipais para a referida análise, principalmente no que se refere a microdados bancários. Ainda de forma incipiente, procura-se avaliar através de um modelo Logit Ordenado quais as chances de um município se apresentar com alto ou baixo número de patentes em função das seguintes variáveis bancárias: acesso bancário, crédito, depósitos e inserção bancária. Os resultados apresentam fortes indícios de que uma maior presença de bons indicadores financeiros aumenta as probabilidades de sustentação da inovação e de que a alta concentração de ambas as esferas (tecnológica e financeira) atesta a forte relação entre inovação, crédito e espaço.

\footnotetext{
* Uma versão deste artigo foi apresentada no XII Encontro Nacional de Economia Política. Os autores agradecem os comentários, críticas e sugestões de três pareceristas anônimos da revista. Os erros são de responsabilidade exclusiva dos autores.
} 
Palavras-Chave | Patentes; Crédito; Sistema de Inovação; Sistema Financeiro; Economia Regional

Códigos JEL | O31; O32; R12; R51; C25; E44

\section{Abstract}

This paper assesses the relationships between patents and banking variables. The main feature of the paper is the use of micro-data for quantitative and qualitative analyses that deal with financial and innovation variables at the level of municipalities. Drawing upon a Logit Model, the paper states that the probability of a municipality having high or low quantity of patents varies according to the higher or lower presence of banking variables such as bank access, credit, demand deposits and local insertion in the banking activity. The results generally point out to a positive relationship between innovation and financial variables and also show that the high concentration of the financial and technological variables is responsible for a strong interaction between innovation, credit, and space.

KEYWORDs I Patents; Credit; Innovation System; Financial System; Regional Economics

JEL-Codes I O31; O32; R12; R51; C25; E44 


\section{Introdução}

A relação entre sistemas financeiros e sistemas de inovação é um tema importante que recentemente vem recebendo atenção maior na literatura da economia da tecnologia. Essa importante lacuna na literatura, reconhecida entre outros por O'Sullivan (2004), exige uma discussão cuidadosa e certamente demanda diálogos entre diferentes abordagens da economia.

É verdade que o tema mais geral das relações entre financiamento e desenvolvimento, em especial discussões relacionadas às relações causais entre avanços na dimensão financeira e seus efeitos sobre o desenvolvimento em geral, tem sido objeto de algumas controvérsias importantes (ver, por exemplo, o debate entre King \& Levine, 1993, e Arestis \& Demetriades, 1997, 1998). Para os economistas voltados para a temática da tecnologia, o interessante é observar o tema desse debate: Estaria Schumpeter certo?

Essa atenção limitada ao tema da relação entre sistemas financeiros e sistemas de inovação em uma literatura de forte inspiração schumpeteriana é paradoxal. Em A teoria do desenvolvimento econômico, Schumpeter (1985) destacou enfaticamente a relação entre o empresário e o sistema bancário (provedor de crédito) e atribuiu ao mercado monetário (no capítulo III, sobre crédito e capital) um papel central: "o mercado monetário é sempre, por assim dizer, o quartel-general do sistema capitalista” (1985:86). O virtual desaparecimento dessa temática (relação entre o sistema financeiro e a dinâmica inovativa) no livro que Schumpeter lança em 1942 (Capitalismo, socialismo e democracia, 1984) merece uma discussão à parte.

Entretanto, a sistemática preocupação de Schumpeter com a questão financeira pode ser constatada em duas obras póstumas: History of economic analysis e Das Wesen des Geldes. Infelizmente, as elaborações teóricas influenciadas pela obra de Schumpeter (os neo-schumpeterianos) acabaram deixando o tema de fora das preocupações centrais, possivelmente mais influenciados pelas formulações do Schumpeter autor de Capitalismo, socialismo e democracia. O resultado é a existência da lacuna identificada por O’Sullivan.

Autores identificados com a abordagem neo-schumpeteriana têm buscado contribuir para minorar essa importante lacuna: destacam-se Chesnais 
(2004), Perez (2002) e O’Sullivan (2004).' François Chesnais tem trabalhado há mais tempo em torno das metamorfoses do capitalismo, em especial na articulação entre globalização e finanças internacionais (Chesnais, 1994, 1996). Em trabalhos mais recentes, tem chamado atenção para uma possível nova fase do capitalismo com a emergência de um regime de acumulação global dominado pelo capital financeiro (ver, como exemplo, Chesnais, 2004).

Carlota Perez (2002) apresenta uma articulação entre a dinâmica das revoluções tecnológicas que impulsiona as "ondas longas do desenvolvimento capitalista" e o papel da relação entre o "capital produtivo" e o "capital financeiro" nas diversas fases do movimento cíclico. Perez focaliza as novas empresas e novas indústrias que alimentam a revolução tecnológica que abre cada nova fase do capitalismo e investiga como são financiadas. A partir da existência de acoplamento e desacoplamento entre instituições ao longo das mudanças de paradigmas, Perez sugere quatro tipos de relacionamento entre o capital produtivo e o financeiro (2002:74):

$$
\begin{aligned}
& 1 \text { - irrupção (love affair); } \\
& 2 \text { - frenesi (desacoplamento); } \\
& 3 \text { - sinergia (re-acoplamento); } \\
& \text { 4- maturidade ("sinais de separação"). }
\end{aligned}
$$

Mary O'Sullivan (2004) discute o papel das finanças na economia da inovação, identificando a negligência da questão financeira na economia da inovação contemporânea. Apoiada na proposta de integração entre economistas da inovação e historiadores especializados na questão financeira, O’Sullivan apresenta uma agenda de pesquisa (O'Sullivan, 2005; Lamoreaux et al., 2004) que aparentemente tem progredido, junto com os trabalhos citados anteriormente, para a sistematização de casos e elementos empíricos que enriquecem o estudo das relações entre sistemas financeiros e sistemas de inovação.

\footnotetext{
1 Entre as contribuições anteriores mais importantes, destacam-se Christensen (1992) e Goodcare e Tonks (1995). No Brasil, autores como Mello (1994), Erber (1999), Campelo (2000) e Corder e Salles-Filho (2006) têm contribuições para o tema.
} 
Este artigo tem um objetivo específico: focalizando o caso brasileiro, apresentar um exercício exploratório sobre as relações entre essas duas dimensões, a partir de dados sobre atividade bancária (uma proxy do sistema financeiro) e sobre patentes (uma proxy do sistema de inovação).

Porém, não é possível uma apresentação direta desses dados sem a tentativa inicial de definir conceitualmente uma hipótese sobre as relações de causalidade entre sistemas financeiros e sistemas de inovação. Posteriormente, é necessário compreender a localização do Brasil no cenário internacional em relação a essas duas variáveis, para que os dados aqui apresentados possam ser compreendidos criticamente. Essa contextualização é importante porque a literatura discutida acima toma por referência fundamentalmente os países avançados.

Com essas medições e qualificaçōes, este artigo avalia os dados para o Brasil tomando o município como referencial para análise. Procura-se estudar, ainda de forma incipiente e através de um modelo Logit Ordenado, quais as chances de um município se apresentar com alto ou baixo número de patentes em função de variações das seguintes variáveis bancárias: acesso bancário, crédito, depósitos e inserção bancária. Esse modelo permite investigar um dos sentidos da causalidade entre finanças e inovação, o que define o exercício estatístico desenvolvido neste artigo como inicial e exploratório, a ser necessariamente secundado por novos estudos para tentar dar conta da complexidade dos padrōes de interação entre essas duas dimensões.

Para conseguir esses objetivos, a seção 1 realiza uma breve discussão teórica acerca do tema e situa a posição do Brasil no cenário internacional. A seção 2 apresenta os dados e suas fontes e discute a metodologia adotada. A seção 3 avalia os resultados encontrados e, por fim, a conclusão é apresentada na seção 4 .

\section{Sistema de inovação e sistema financeiro: efeitos recíprocos em operação}

Para uma discussão introdutória da relação entre as duas dimensões (que ao longo deste texto serão tratadas como dimensão monetário-financeira e dimensão industrial-inovativa), a obra de Marx pode constituir-se em um ponto de partida valioso. A simultaneidade entre causa e efeito e a identificação 
de efeitos recíprocos entre mudanças na dimensão monetário-financeira e industrial-inovativa sintetizam um enfoque introdutório de Marx sobre o tema e justificam uma análise mais detalhada da sua elaboração. ${ }^{2}$

Possivelmente a lógica que fundamenta essa simultaneidade entre causa e efeito vem sendo discutida desde os Grundrisse, nos quais Marx indica uma relação entre o dinheiro, a divisão de trabalho e o seu aperfeiçoamento. $\mathrm{O}$ dinheiro e as relações monetárias desenvolvem-se em sintonia com a divisão de trabalho, isto é, diz Marx, com o crescente caráter social da produção (1973:146). Na medida em que cresce o caráter social da produção, portanto a divisão do trabalho, também cresce o "poder do dinheiro" (Marx, 1973:146). Mais adiante, Marx especifica ainda mais essa relação, especificando a sua gênese, ao afirmar que "o dinheiro oferece a possibilidade de uma divisão absoluta do trabalho" (1973:200). Evidentemente esse ponto é derivado de Adam Smith, que no capítulo IV, livro I, ao tratar da "Origem e uso do dinheiro", aponta o papel da divisão de trabalho (1983:126-131) nessa gênese.

Essa relação entre dinheiro e divisão de trabalho pode ser traduzida como uma relação entre o dinheiro (e sistema monetário) e melhoras na produtividade, logo, progresso técnico. A primeira forma de progresso técnico exposta pela nascente economia política é exatamente a divisão do trabalho, exemplificada na célebre descrição e análise de Adam Smith sobre a manufatura de alfinetes. Essa descrição é apropriada pela economia industrial contemporânea nas suas discussões sobre o progresso técnico e seus determinantes (Scherer, 1990), indicando aliás a divisão de trabalho e sua contrapartida, a especialização, como um dos motores persistentes do progresso tecnológico ao longo dos séculos XIX e XX.

Marx, ao tratar dos processos de centralização e concentração de capital (o processo de desenvolvimento da grande empresa, no linguajar mais tradicional da economia industrial), processos estes decisivos na dinâmica de acumulação de capital, aponta o papel das sociedades por ação como viabilizadoras dos investimentos necessários. O sistema de crédito é reconhecido explicitamente como acelerando o desenvolvimento material das forças produtivas e a criação do mercado mundial (Marx, 1981:572). Esse sentido de causalidade acom-

2 Para uma exposição mais detalhadas de um método identificado na obra de Marx para a avaliação das relações entre finanças e inovação, ver Albuquerque (2008). 
panha o comentário de Marx sobre as ferrovias, a centralização de capitais e as sociedades por ação (1976:780).

Em outro nível de análise, Marx indica que o "desenvolvimento pleno do sistema bancário e de crédito” (1981:742) é um pré-requisito para o modo de produção capitalista. Desde o início, esse desenvolvimento institucional possibilita a emergência de uma divisão mais complexa entre os diversos capitais (comercial, monetário, industrial), com uma divisão de trabalho funcional entre eles. Isso traz novas possibilidades de desenvolvimento, com o sistema bancário impulsionando a produção capitalista para além de seus limites, ao mesmo tempo em que abre novas fontes de crises.

O significado do sistema de crédito no sistema capitalista é uma antiga preocupação de Marx, certamente alimentada pela forma como os socialistas proudhonianos abordavam o tema. O tema do primeiro capítulo dos Grundrisse é o dinheiro e esse capítulo é iniciado por uma leitura crítica de um livro sobre bancos de um autor proudhoniano (Alfred Darimon). Nessa crítica, que se relaciona a todo um esforço de pesquisa e investigação de Marx sobre o dinheiro, as posições de socialistas em relação ao moderno sistema de crédito são avaliadas detalhadamente (o tema reaparece no terceiro volume de $O$ capital, no qual os saint-simonianos são o objeto principal da crítica). Nessas reflexões, Marx indica uma certa unilateralidade nas análises de Darimon e outros que insistiam no papel do crédito na evolução do sistema capitalista. Marx, ao criticar essa unilateralidade, afirma que "as modernas instituiçôes de crédito seriam tanto uma causa como um efeito da concentração de capital” (p.122).

Marx mantém esse padrão de relação entre as duas dimensões após as pesquisas e elaborações realizadas posteriormente aos Grundrisse. No terceiro volume de $O$ capital, ao discutir as relações entre "capital monetário e capital real”, Marx ressalta as relações entre crédito comercial e produção em grande escala para mercados distantes, anotando que o crédito é indispensável aqui. $\mathrm{Na}$ seqüência do raciocínio, Marx novamente sugere a existência de efeitos recíprocos entre crédito e indústria: "[...] crédito que cresce em volume com o crescimento e cresce em duração com o aumento da distância dos mercados”. Então, "um efeito recíproco tem lugar aqui. O desenvolvimento do processo de produção expande o crédito enquanto o crédito por sua vez leva a uma expansão de operações industriais e comerciais" (Marx, 1981:612). 
De uma forma mais geral, a elaboração de Marx sugere pelo menos cinco conexões entre as duas dimensões.

Uma primeira conexão articula a expansão da produção material com a expansão da acumulação monetária. O capítulo 32 abre-se com uma referência à "maciça soma de dinheiro que [...] é o resultado da escala maciça do processo de reprodução". Vale repetir: o processo de produção material gera enormes massas monetárias. Essas massas monetárias devem ser retransformadas em capital. Essas massas monetárias em expansão implicam a expansão dos capitalistas monetários. O que, por sua vez, implica que "o sistema de crédito deva desenvolver-se mais" (Marx, 1981:642-643).

Uma segunda conexão articula a expansão monetária com novos empreendimentos. Essa expansão, que também pode ser conseqüência do desenvolvimento do sistema bancário (Marx, 1981:619), abre uma fase na qual, segundo Marx, haveria uma "grande expansão de capital fixo em todas as formas" e a “abertura de um grande número de novas empresas" (1981:619-620).

Uma terceira conexão articula uma dinâmica entre mudanças quantitativas e qualitativas. A acumulação de massas monetárias maiores e a maior disseminação dos mecanismos de crédito abrem espaço para inovações institucionais na esfera monetário-financeira.

Uma quarta conexão envolve ainda a relação entre mudanças qualitativas e quantitativas, mas em um sentido inverso ao do anterior. A ampliação da escala da produção, no sentido de uma maior importância dos investimentos em capital fixo (a tendência histórica ao crescimento da composição orgânica do capital), determina à dimensão industrial-inovativa novas demandas sobre o capital monetário e seu ramo especial de negócios. Para a realização de investimentos maiores, novas instituições são necessárias. Como Minsky (1986:317) coloca, um mercado de títulos e de ações é um "complemento necessário" (necessary adjunct) para a sociedade anônima como forma de organizar negócios.

Finalmente, vale o fato de que a conexão entre as duas dimensões está longe de ser simétrica, equilibrada e destituída de conflitos. Em relação às crises, um dos pontos fortes da elaboração de Marx é o papel contraditório que o crédito desempenha para a dinâmica capitalista. Se por um lado, como até aqui foi ressaltado neste texto, o crédito garante a fluidez do processo 
de produção e multiplica as oportunidades do processo de acumulação de capital, por outro abre novas possibilidades de irrupção de crises, ampliando a instabilidade do sistema. Nesse sentido, aqui também a elaboração de Marx pode dialogar com a de Minsky, que desde outro referencial teórico afirma ser a estrutura financeira "causa tanto da adaptabilidade como da instabilidade do capitalismo" (Minsky, 1986:175).

Para os objetivos deste artigo, essas cinco conexões ilustram as diversas determinaçõos envolvidas nas relações entre a dimensão financeira e a inovativa e ampliam as noções gerais de simultaneidade entre causa e efeito e de efeitos recíprocos entre as duas dimensōes. Para a organização de um diálogo entre neo-schumpeterianos e pós-keynesianos (a falta desse diálogo é uma limitação importante nas elaborações de O'Sullivan, Chesnais ou Perez), as conexões indicadas podem contribuir na medida em que fortalecem os esforços realizados no entendimento da dimensão industrial-inovativa por economistas neo-schumpeterianos e da dimensão monetário-financeira investigada por economistas pós-keynesianos.

A afirmação de que a relação entre a dimensão financeira e inovativa envolve mútua causalidade e mútua determinação serve como uma síntese do que até aqui foi apresentado nesta seção e fundamenta a compreensão deste artigo a respeito de como investigar empiricamente a relação entre essas suas dimensões. Certamente, uma investigação a ser desenvolvida é o das diversas conexões entre as duas dimensões e os canais através dos quais essa mútua causalidade atua.

Até aqui, a argumentação desta seção enfatizou a natureza histórica e intertemporal das relações entre as duas dimensões. Para tratar de um país como o Brasil, que será avaliado nas próximas seções, outro aspecto deve ser introduzido: a investigação de padrões de co-evolução entre as duas dimensões entre diferentes estágios de desenvolvimento. A obra de Gerschenkron (1962) pode ser um excelente ponto de partida: na discussão dos processos de catching up, o papel dos bancos para a superação do atraso econômico é destacado. A forma particular, tanto da simultaneidade entre causa e efeito quanto da dinâmica de efeitos recíprocos, pode ser objeto de investigação. Recentemente, a literatura econômica tem buscado investigar esse tema mais geral, resenhada por Levine (1997). Na literatura que envolve os trabalhos 
de Levine, assume-se um sentido para a causalidade, mais precisamente das instituições financeiras para o desenvolvimento das nações. Diversos trabalhos têm criticado a abordagem de unidirecionalidade da causalidade assumida; trabalhos como os de Arestis e Demetriades, (1997); Arestis, Demetriades e Fattouh, (2003); Arestis, Nissanke e Stein, (2005); Arestis, Chortareas e Desli (2006) apontam problemas metodológicos que, se corrigidos, não confirmam a direção causal. Contrariamente, não existiria causalidade definida a priori, cabendo aos diferentes arcabouços institucionais de cada país o papel de definidor da relação entre sistema financeiro e crescimento econômico. Essa abordagem abre espaço para o entendimento da mútua determinação como o melhor caminho para a investigação de tal objeto de estudo.

Para localizar o caso brasileiro, é útil a referência de uma sistematização de informaçōes estatísticas relacionadas ao tema compiladas por Herskovic (2007).

Herskovic elaborou o Gráfico 1 (abaixo) a partir de dados de PIB per capita (para a riqueza das naçōes), patentes e artigos científicos por milhão de habitantes (para a produção científico-tecnológica), crédito ofertado pelo sistema bancário e capitalização de mercado das empresas listadas na bolsa de valores (para a dimensão financeira). O Gráfico 1 indica uma correlação entre dados relativos à riqueza das nações, à produção científico-tecnológica e à dimensão monetário-financeira.

Para além de uma pista empírica no tocante a essa correlação geral, que fortalece os argumentos em relação ao padrão de causalidade discutido nesta seção, e para os objetivos deste artigo, os dados desse gráfico são úteis para contextualizar a posição do Brasil, servindo assim de introdução à próxima seção. Herskovic (2007:42-44) aplica técnicas de agrupamento para diferenciar os países no espaço tecnologia e finanças (grosso modo, o eixo xy do Gráfico 1). O resultado indica que o Brasil se encontra no grupo dos países em posição intermediária (no mesmo grupo do México, da África do Sul e da Argentina). O grupo acima é composto por países de alta renda per capita, alta produção científica e tecnológica e sistemas monetário-financeiros bem desenvolvidos (Estados Unidos, Japão e Alemanha, por exemplo, estão nesse grupo). ${ }^{3}$ No grupo abaixo estão os países mais pobres (Bolívia, Gana, Marrocos, por exemplo).

3 As diferenças entre esses três países em termos dos sistemas financeiros foram extensivamente discutidas por Zysman (1982). 


\section{GRÁFICO 1}

Logaritmo de PIB per capita (2003), TEC (variável que engloba a produção científica e tecnológica, média do período 1999-2003) e FIN (variável que engloba a dimensão dos bancos e das bolsas de valores, dados para 2003)

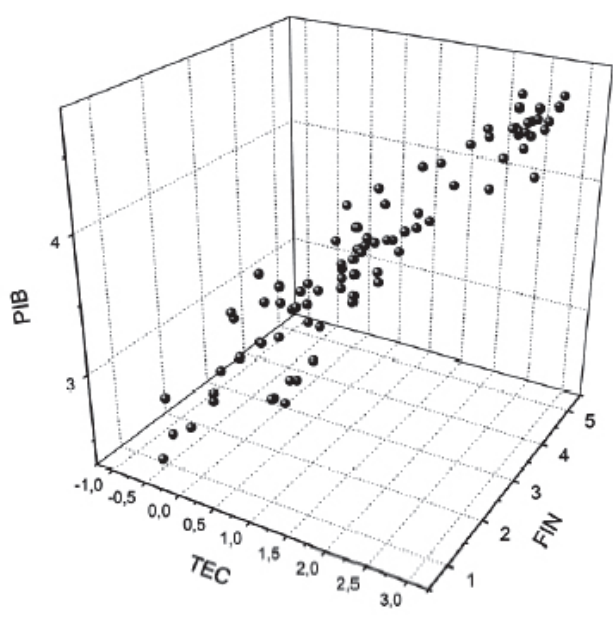

Fonte: Herskovic (2007), elaboração a partir do USPTO, ISI e Banco Mundial.

A identificação da posição brasileira, então, serve como uma introdução à próxima seção, na qual os dados para o Brasil são apresentados. Essa posição sugere que as investigações sobre o caso brasileiro devam levar em conta particularidades como a existência de um sistema de inovação imaturo e de um sistema financeiro não-funcional.

\section{Apresentação dos dados e metodologia}

Uma vez ilustrada a posição internacional do Brasil, esta seção apresenta os dados para o caso brasileiro. Nessa análise, o espaço geográfico é uma variável decisiva. Dadas as características continentais do Brasil, a análise da distribuição espacial das atividades relacionadas a finanças e inovação é indispensável.

A parte empírica deste trabalho tem como objetivo relacionar a maior ou menor capacidade inovativa de uma região com características de seu 
sistema financeiro. Duas fontes de dados principais foram combinadas: variáveis financeiras foram fornecidas pelo Laboratório de Estudos sobre Moeda e Território (LEMTe) do CEDEPLAR-UFMG e variáveis de inovação foram fornecidos pelo Grupo de Economia da Ciência e Tecnologia do CEDEPLAR-UFMG. Como já mencionado, a novidade deste trabalho está na forma de apresentação dos dados, qual seja: municípios. Do ponto de vista de patentes, isso já é amplamente utilizado. Já, do ponto de vista de dados do sistema financeiro, nem tanto. São poucos os trabalhos realizados até hoje que se utilizam desse recorte. Isso só é possível devido ao trabalho de coleta e sistematização de dados bancários municipais realizados pelo Laboratório de Estudos em Moeda e Território (LEMTe) do CEDEPLAR da UFMG.

\subsection{Fonte de dados}

A dimensão financeira deste trabalho consiste no agregado dos balancetes mensais do sistema bancário em nível municipal ${ }^{4}$ para os anos de 1999, 2000 e 2001. Os dados financeiros utilizados têm periodicidade mensal e, com o intuito de captar com maior fidelidade a estrutura financeira municipal brasileira, foi calculada a média no período entre janeiro de 1999 e dezembro de 2001, consolidando as informações de 36 balancetes. O deflator utilizado para equiparar os dados mensais foi o índice IPCA, tendo como mês-base janeiro de 2006.

A metodologia de coleta de dados desenvolvida pelo LEMTe-CEDEPLAR permitiu adquirir balancetes para uma parcela significativa dos municípios brasileiro, o equivalente a 59\% do total de municípios brasileiros. Este trabalho se limita a analisar os municípios com pelo menos três agências em algum dos meses do período. Isso se deve ao fato de o Banco Central, para evitar problemas de identificação, somente disponibilizar a agregação de no mínimo três agências. ${ }^{5}$ Apesar de representarem 36\% das cidades com dados

\footnotetext{
4 Desde a reforma bancária de 1988, exige-se que toda agência de bancos comerciais, bancos múltiplos com carteira comercial e caixas econômicas envie ao BACEN a posição contábil do último dia útil de cada mês. Esses dados são catalogados no documento Estatística Bancária Mensal (ESTBAN) do Plano Contábil das Instituições do Sistema Financeiro Nacional (COSIF) e são disponibilizados ao público através da transação PCOS660 do Sistema de Informações do Banco Central (SISBACEN).

5 As diferenças entre esses três países em termos dos sistemas financeiros foram extensivamente discutidas por Zysman (1983).
} 
financeiros disponíveis, os 1.182 municípios da amostra utilizada neste trabalho concentram a parte mais significativa do sistema financeiro brasileiro: contabilizaram $93,4 \%$ do total dos depósitos à vista, 97,8\% dos depósitos a prazo, 97,9\% das operações de crédito e 99,3\% das receitas de todas as agências bancárias brasileiras. Enquanto isso, essas mesmas cidades respondem por $72,1 \%$ da população e $85,2 \%$ do PIB. Verifica-se, assim, uma concentração das variáveis financeiras muito maior que a já significativa concentração regional de variáveis reais.

Do lado das variáveis de inovação, foram utilizados dados de registro de patentes e de autoria de artigos científicos. Entre 1999 e 2001 foram registradas 16.885 patentes no Instituto Nacional da Propriedade Intelectual (INPI), distribuídas em 886 cidades. Destas, cerca de um quarto são patentes de pessoas jurídicas e três quartos, de pessoas físicas. Finalmente, 19.266 autores com artigos indexados pelo Institute for Scientific Information (ISI) em 2000 se distribuem em apenas 229 cidades. Coletado os dados financeiros, de patentes e de produção científica, o passo seguinte foi agrupá-los na forma de microrregiōes proposta pelo IBGE. Na dimensão financeira, os 1.182 municípios que satisfazem o critério de ter ao menos três agências no período correspondem a 436 microrregiōes (78\% das microrregiōes brasileiras). $\mathrm{Na}$ dimensão da inovação, as 886 cidades se agrupam em 322 microrregiōes e, já na dimensão científica, as 229 se agrupam em 162 micros. Dados agrupados por microrregiōes podem ser vislumbrados na Tabela 1 .

Visualizando a primeira coluna da Tabela 1 referente aos índices de concentração das variáveis, percebe-se que o crédito ofertado e o número de patentes registradas possuem o mesmo coeficiente, o que remete à proximidade da relação entre o grau de concentração do crédito ofertado e do número de patentes. As agências foram as que apresentaram menor grau e concentração espacial $(0,69)$. Ainda com relação às variáveis financeiras, as receitas dos bancos e o total do ativo foram as que tiveram maior fator concentrador $(0,96$ e 0,95 respectivamente). Com relação à natureza do registro da patente, as relativas à pessoas jurídicas apresentam maior concentração.

Pode-se verificar a alta amplitude dos intervalos de dados. A oferta de crédito varia de 2,68 milhões de reais até 209 bilhões de reais, cifras que são acompanhadas pelas outras variáveis. A média de patentes por microrregião é 52 . 
TABELA 1

Descrição das variáveis agregadas em microrregião

\begin{tabular}{|c|c|c|c|c|c|c|c|}
\hline Variável & Gini* & Soma & Freq. & Média & $\begin{array}{l}\text { Desvio- } \\
\text { padrão }\end{array}$ & Máximo & Mínimo \\
\hline População em 2000 & 0,5882 & 169.791.794 & 567 & 299.456 & 794.158 & 12.788 .974 & 2.051 \\
\hline Agências bancárias & 0,6673 & 16.174 & 547 & 29 & 107 & 2.047 & 1 \\
\hline Depósitos à vista públicos & 0,7836 & 5.267 & 436 & 12 & 46 & 577 & 0,173 \\
\hline Depósitos à vista privados & 0,8518 & 52.762 & 436 & 121 & 790 & 14.603 & 0,415 \\
\hline Lucro & 0,8543 & 2.336 & 436 & 5 & 25 & 340 & 0,007 \\
\hline Créditos & 0,9133 & 530.414 & 436 & 1.217 & 10.721 & 209.251 & 3 \\
\hline Total do ativo ( $\mathrm{R} \$ \mathrm{mi})$ & 0,9542 & 2.201 .363 & 436 & 5.049 & 54.757 & 1.076 .007 & 9 \\
\hline Receitas & 0,9682 & 44.560 & 436 & 102 & 1.252 & 25.284 & 0,163 \\
\hline Patentes & 0,8620 & 16.885 & 322 & 52 & 307 & 5.130 & 1 \\
\hline de pessoa física & 0,8518 & 12.619 & 311 & 39 & 224 & 3.724 & 0 \\
\hline de pessoa jurídica & 0,9198 & 4.266 & 158 & 13 & 84 & 1.406 & 0 \\
\hline Produção científica & 0,8712 & 19.226 & 162 & 119 & 452 & 3.841 & 1 \\
\hline
\end{tabular}

* Calculado segundo a fórmula Gini $=\sum\left(\mathrm{X}_{\mathrm{K}}-\mathrm{X}_{\mathrm{K}-1}\right) /\left(\mathrm{Y}_{\mathrm{K}}+\mathrm{Y}_{\mathrm{K}+1}\right)$.

Fonte: LEMTe-CEDEPLAR.

\subsection{Distribuição regional}

Nesta subseção são analisadas a distribuição geográfica das agências, do crédito, das patentes e da produção científica entre as microrregiōes.

A partir da Tabela 2, pode-se inferir sobre a alta concentração do registro de patentes nas microrregiōes com capitais brasileiras. Das 11 primeiras microrregiōes em número de patentes, 10 são micros com capitais de seus respectivos estados federativos. Percebe-se assim o forte fator concentrador da inovação, que surge amparada pela forte concentração regional das atividades econômicas brasileiras. 
TABELA 2

20 principais microrregiões ordenadas por quantidade de patentes

\begin{tabular}{|c|c|c|c|c|c|c|}
\hline Microrregião & UF & Região & Agências & Crédito* & Patentes & Prod. científica \\
\hline São Paulo & $\mathrm{SP}$ & SE & 2.047 & 94.168 & 5.130 & 3.841 \\
\hline Rio de Janeiro & RJ & SE & 1.187 & 16.381 & 1.259 & 3.511 \\
\hline Belo Horizonte & MG & SE & 431 & 5.918 & 901 & 1.092 \\
\hline Curitiba & PR & S & 320 & 3.844 & 781 & 440 \\
\hline Porto Alegre & RS & S & 439 & 5.703 & 731 & 1.003 \\
\hline Campinas & $\mathrm{SP}$ & SE & 283 & 3.323 & 549 & 1.809 \\
\hline Caxias do Sul & RS & S & 101 & 841 & 405 & 20 \\
\hline Brasília & DF & $\mathrm{CO}$ & 257 & 8.129 & 329 & 396 \\
\hline Osasco & $\mathrm{SP}$ & SE & 118 & 19.129 & 284 & 1 \\
\hline São José dos Campos & $\mathrm{SP}$ & SE & 118 & 719 & 226 & 243 \\
\hline Recife & PE & NE & 207 & 2.264 & 170 & 380 \\
\hline Ribeirão Preto & $\mathrm{SP}$ & SE & 149 & 1.296 & 158 & 651 \\
\hline Vitória & ES & SE & 116 & 1.014 & 156 & 92 \\
\hline Sorocaba & $\mathrm{SP}$ & SE & 116 & 745 & 153 & 3 \\
\hline Fortaleza & CE & $\mathrm{NE}$ & 156 & 2.267 & 139 & 305 \\
\hline Goiânia & GO & $\mathrm{CO}$ & 159 & 1.485 & 136 & 106 \\
\hline Salvador & BA & NE & 239 & 3.810 & 123 & 214 \\
\hline São José do Rio Preto & SP & SE & 119 & 603 & 104 & 79 \\
\hline Santos & $\mathrm{SP}$ & SE & 139 & 716 & 79 & 14 \\
\hline Belém & PA & $\mathrm{N}$ & 98 & 859 & 26 & 201 \\
\hline
\end{tabular}

* Em milhões de $R \$$.

Fonte: LEMTE-CEDEPLAR.

Observa-se também que a ordenação não é a mesma para todas as variáveis. Em relação à produção científica, nota-se que as microrregiōes de Curitiba, Caxias do Sul, Osasco, Vitória e Sorocaba possuem produção científica nitidamente inferior ao número de patentes. Curitiba, por exemplo, está ordenada em terceiro lugar em termos de patente e sétimo em termos de produção científica. Os casos de Osasco e Caxias do Sul são ainda mais marcantes. A primeira está classificada em nono lugar em termos de patentes (284) e possui apenas 1 artigo científico. De forma semelhante, Caxias do Sul 
apresenta 405 patentes, o que a coloca em sétimo lugar, mas possui apenas 20 artigos científicos.

Esse mesmo fenômeno acontece quando se compara a quantidade de crédito concedido e a produção de patentes. Microrregiōes com maior número de patentes não necessariamente possuem um maior volume de crédito. Esse fenômeno poderia ser explicado devido ao fato de que tanto o crédito ofertado quanto a produção científica respondem a outros fatores que não afetam, diretamente, o número de patentes. A concessão de crédito, por exemplo, está relacionada tanto à dinâmica econômica de uma microrregião quanto à sua dimensão urbana. Já a produção científica estaria relacionada à distribuição espacial de universidades e centros de pesquisa. Na linguagem de economia regional, poder-se-ia dizer que as variáveis são afetadas pelo grau de centralidade da referida microrregião (Christaller, 1966).

A relação entre centralidade e inovação pode ser entendida através da contextualização do trabalho de Christaller sobre lugares centrais. Cavalcante (2006) expõe e relaciona o lugar central ao sistema financeiro, contexto que pode ser estendido para a compreensão da inovação. Para que fatores como tamanho distintos de cidades e sua distribuição irregular no espaço sejam explicados, Christaller (1966) interpõe a lógica da concentração e centralização provocada pela relação entre oferta e demanda de diferenciados serviços:

"A centralidade caracteristica de um lugar central é um atributo ligado diretamente à densidade de população e as atividades econômicas existentes em uma determinada regiāo, permitindo o fornecimento de bens e serviços centrais tais como, comércio atacadista e varejista, serviços bancários, organizaçôes de negócios, serviços administrativos, facilidades de educação e diversão, etc. O lugar central atua como um centro de serviços para si mesmo e para áreas imediatamente próximas (regiäo complementar). A partir desta definição, Christaller (1966) admite a existência de uma hierarquia de lugares centrais de acordo com a menor ou maior disponibilidade de bens e serviços oferecidos por uma localização (bens e funçôes centrais). A ordem de um bem ou função central é tão maior quanto mais sofisticado for este bem e maior for sua área de mercado". (Cavalcante, 2006:54) 
Tal contexto também pode ser aplicado à inovação. Considerando que a inovação tenha uma relação positiva com centros de pesquisa e universidades, ou seja, serviços de educação e pesquisa, então existe uma relação explícita entre um alto grau de centralidade de uma localidade (que reúne tanto sofisticação dos serviços como alta densidade), a existência de centros de pesquisa e a prática da inovação. Espera-se que locais de alta centralidade proporcionem um ambiente mais propício à inovação, não somente porque reúnem serviços gerais em maior escala e mais sofisticados, como também essas atividades de inovação se beneficiem de externalidades positivas derivadas do lugar onde se manifestam.

Aqui reside o caráter exploratório deste artigo. Parte da literatura sobre desenvolvimento financeiro e crescimento econômico tem como base o princípio causal explorado aqui: o sistema financeiro (ou o banqueiro na concepção de Schumpeter) é o responsável por financiar a inovação, geradora de um novo impulso de desenvolvimento pelo qual a economia entra num ciclo de crescimento. Essa mesma literatura ainda não foi capaz de determinar qual a causalidade entre desenvolvimento financeiro e crescimento econômico, e certamente esse não é o intuito deste trabalho. Antes de definir uma causalidade trivial entre sistema financeiro (financiamento) e inovação (patentes), o importante é investigar o ambiente em que se processa tal relação, considerando que a relação entre as variáveis é recíproca e, portanto, pode-se manifestar diferentemente em cada local e tempo diferente. Não é objetivo deste trabalho determinar tal causalidade e sim, dado a limitação de espaço, analisar apenas um dos lados dessa mútua causalidade.

O Mapa 1 mostra a distribuição das agências bancárias por microrregião brasileira. É notável a concentração das agências nas microrregiões do Sul e do Sudeste, particularmente no estado de São Paulo. No resto do Brasil, as agências tendem a se concentrar no entorno das capitais das Unidades da Federação. Das 64 microrregiōes com pelo menos 45 agências bancárias, 26 estão localizadas em São Paulo, 6 nas micros restantes do Sudeste (Rio de Janeiro, Belo Horizonte, Vitória, Uberlândia, Juiz de Fora, Vale do Paraíba Fluminense) e 16 no Sul (Porto Alegre, Curitiba, Caxias do Sul, Blumenau, Florianópolis, Joinvile, Londrina, Maringá, Joaçaba, Cascavel, Chapecó, Paranavaí, Tubarão, Toledo, Criciúma, Umuarama). Das 16 restantes, isto é, 
MAPA 1

Número médio de agências bancárias por microrregião brasileira (1999-2001)

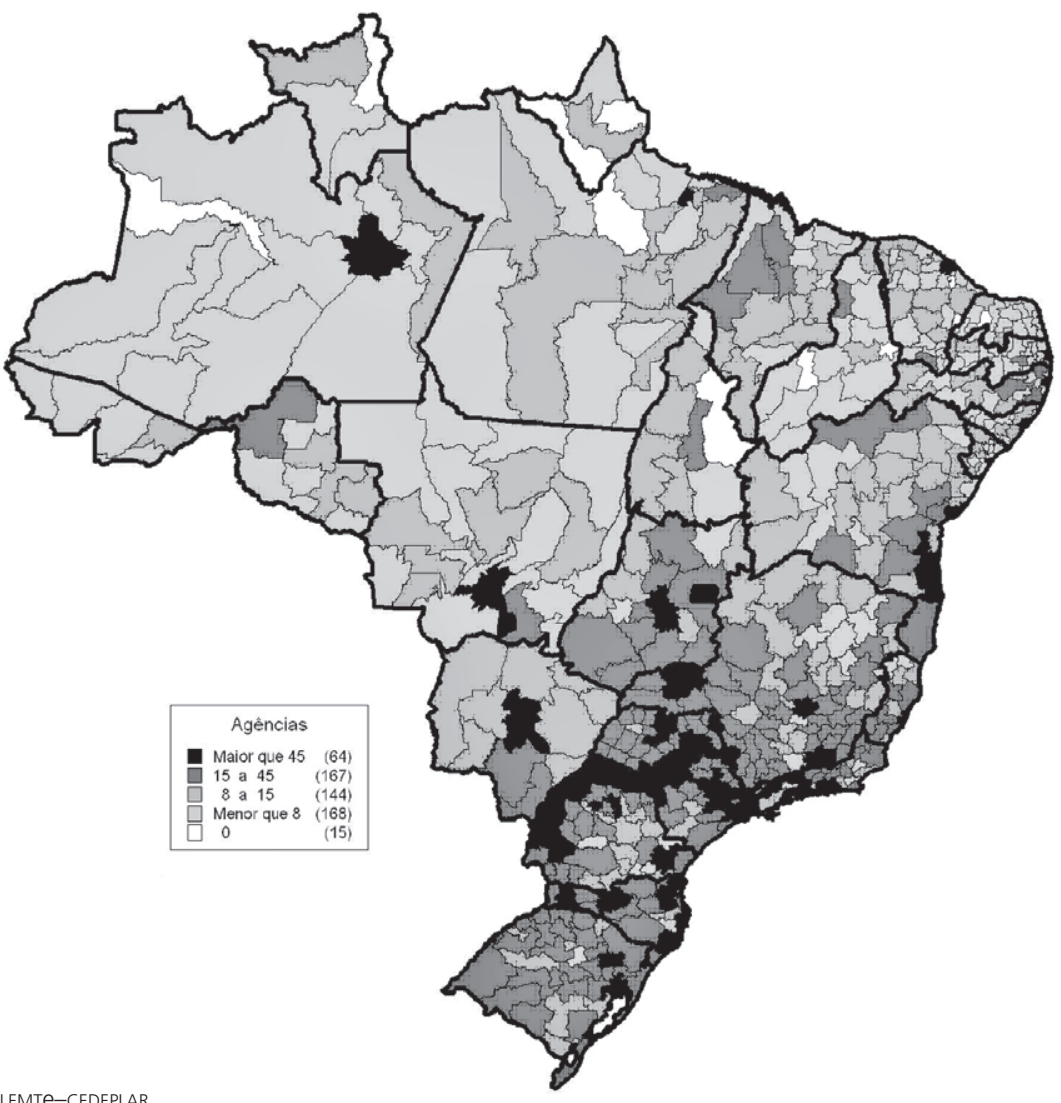

Fonte: LEMTe-CEDEPLAR.

microrregiōes do Centro-Oeste, Norte e Nordeste com pelo menos 45 agências, apenas 2 não contêm capitais das UFs (Ilhéus-Itabuna e Anápolis).

Esse padrão concentrador se repete na segunda categoria de microrregiōes que têm entre 15 e 45 agências. São 167 micros, das quais 135 se situam no Sudeste ou Sul e, das 32 restantes, 17 estão no Nordeste. Nessa categoria aparecem as micros que contêm as capitais de estados: Porto Velho, Porto Nacional (Tocantins) e Teresina. Já na terceira categoria estão presentes algumas regiōes mais periféricas do Sul e Sudeste e microrregiōes de maior centralidade da região Norte (Rio Branco, Macapá e Boa Vista). A quarta categoria representa as demais microrregiōes com agências bancárias. Por fim, 
MAPA 2

Distribuição do crédito bancário entre as microrregiões brasileiras (1999-2001)

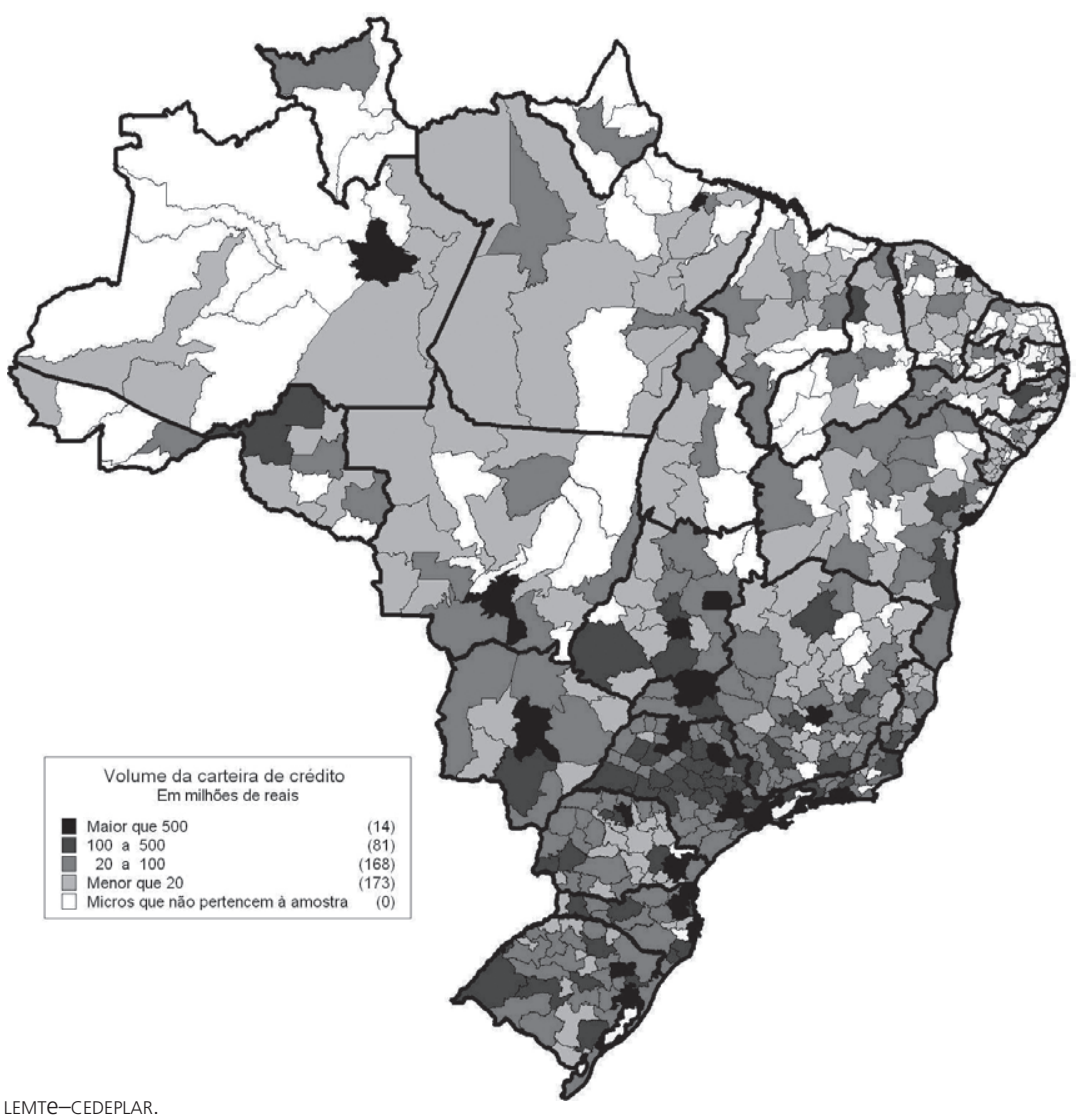

Fonte: LEMTe-CEDEPLAR.

na última categoria estão as micros desprovidas de agências bancárias: 6 no Norte e 9 no Nordeste.

A evidente diferenciação regional na disposição das agências bancárias no Brasil é evidência cabal da concentração das regiōes de maior centralidade ao longo do Sul e Sudeste e em torno das capitais do Nordeste e CentroOeste e de algumas capitais do Norte. Essa diferenciação regional é, no entanto, apenas um prelúdio para a concentração espacial da concessão de crédito bancário no Brasil, cujo coeficiente de Gini é 37\% maior que o da distribuição de agências (ver Tabela 1).

O Mapa 2 permite visualizar a distribuição de crédito bancário entre as 
microrregiōes brasileiras, segundo quatro categorias que variam conforme o volume em estoque na carteira das agências. A primeira categoria, que corresponde às microrregiões com mais de $\mathrm{R} \$ 1$ bilhão de crédito em carteira, tem 14 microrregiōes que juntas representam $83 \%$ do crédito bancário brasileiro. As cinco maiores micros (São Paulo, Osasco, Rio de Janeiro, Brasília e Belo Horizonte) concentram $70 \%$ do crédito da amostra, e a micro de São Paulo concentra sozinha 46\%. Assim como na distribuição regional de agências bancárias, é notável a concentração da categoria mais elevada nas regiōes Sul e Sudeste (9 das 14 ocorrências), particularmente no estado de São Paulo (4). A região Centro-Oeste tem 2 representantes, a região Nordeste, 3 (todas capitais de UF) e a região Norte, nenhum.

A segunda categoria, que contém microrregiões cujas agências bancárias detêm entre R 100 milhões e R $\$ 1$ bilhão em média de créditos em carteira, tem 81 microrregiōes, estando novamente concentradas no Sudeste (41) e no Sul (21). Essa segunda categoria concentra $12,5 \%$ do crédito bancário da amostra.

Dos 4,7\% restantes do crédito bancário, distribuídos em 341 microrregiōes, $3,8 \%$ se encontram na terceira categoria, composta por 168 micros. Mesmo essa categoria ainda é dominada pelas regiões Sudeste e Sul, apresentando ainda as demais capitais do Norte. Na quarta categoria, com 173 micros e responsável por menos de $1 \%$ do crédito bancário brasileiro, pela primeira vez as microrregiōes do Norte e Nordeste são maioria, com 72 e 24 microrregiōes respectivamente. Por fim, são 122 micros que não pertencem à amostra por não conterem municípios com pelo menos 3 agências bancárias: 73 no Nordeste, 27 no Norte, 10 no Sudeste, 10 no Centro-Oeste e 2 no Sul.

Vejamos agora a configuração regional das variáveis de inovação e de produção científica.

Nota-se no Mapa 3 um padrão de distribuição de patentes entre as microrregiōes parecido com o padrão da distribuição do crédito: concentração das categorias mais elevadas no Sul e Sudeste e nas capitais das UFs. Das 27 microrregiōes que detêm mais de 100 patentes, 15 estão localizadas no Sudeste e 7, no Sul. No Sudeste, além das capitais de estado, todas as outras 11 micros estão no estado de São Paulo. No Sul, temos Joinvile, Caxias do Sul, Blumenau e Londrina, além das 3 capitais. As 5 microrregióes restantes 
MAPA 3

Distribuição de patentes entre as microrregiões brasileiras (1999-2001)

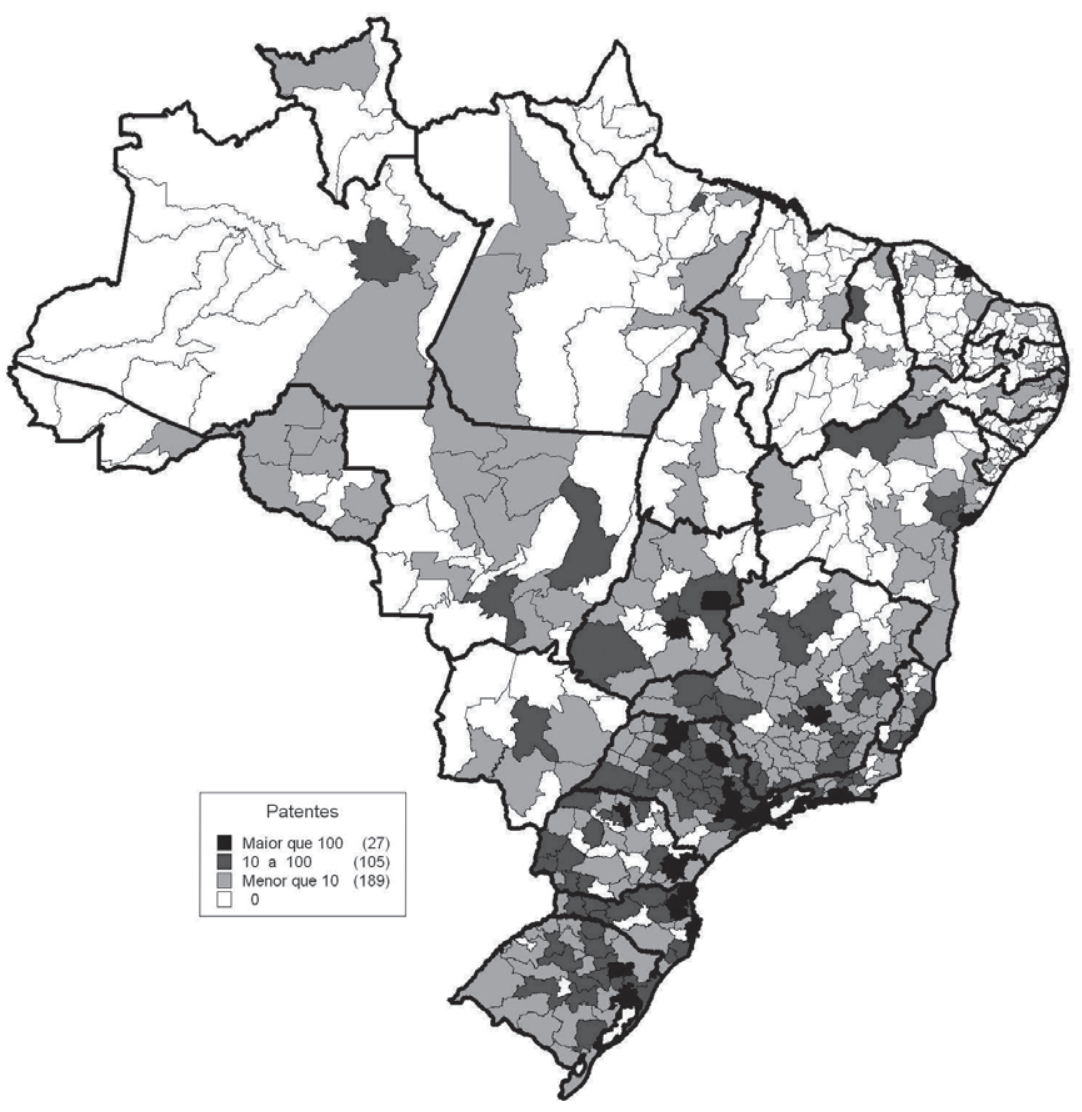

Fonte: LEMTe e Grupo de Economia da Ciência e Tecnologia - CEDEPLAR-UFMG.

da primeira categoria são Brasília, Recife, Fortaleza, Goiânia e Salvador, todas capitais de UF e nenhuma da região Norte. Essa primeira categoria concentra 78,75\% das patentes, sendo 30,4\% somente na micro de São Paulo. Já as 105 microrregiôes da segunda categoria concentram $17,5 \%$ do total de patentes. Essa categoria também está concentrada nas regiōes Sudeste (54 micros) e Sul (34). Das 17 restantes, 9 estão no Nordeste, 6, no Centro-Oeste e 2, no Norte. A terceira categoria registra as microrregiōes com menos de 10 patentes e mesmo esta se concentra nas regiōes Sudeste $(68$ micros) e Sul (39). Na seqüência vêm o Nordeste, com 40, e em seguida o Centro-Oeste e o Norte, empatados com 20 cada. 
Apesar de um padrão de distribuição regional similar ao padrão observado para agências bancárias e crédito, o contraste visual dos dois mapas acima revela diferenças fundamentais nas distribuiçōes das categorias mais superiores, em especial entre Sul e Nordeste. No Mapa 2 verifica-se uma melhor distribuição do crédito em relação a patentes nas regiōes interioranas do Nordeste (em especial nos estados do Maranhão, Piauí, Ceará, Pernambuco e Bahia). Em contrapartida, o interior da região Sul (em especial no Rio Grande do Sul e em Santa Catarina), observa-se o inverso: uma melhor distribuição de patentes, formando "corredores" (embora a distribuição do crédito não seja ruim). Isso poderia ser explicado pela maior presença de fatores que atuam como catalisadores do financiamento da inovação. A presença de corredores de patentes também pode ser explicada (seguindo a lógica da mútua causalidade) pela distribuição das atividades econômicas no espaço e também da distribuição do crédito como imagem dessa distribuição. A presença de instituiçōes mais desenvolvidas em ambientes de menor incerteza promove a oferta de crédito e a proliferação de canais mais consolidados entre agentes, o que propicia o ambiente para a criação e o registro de patentes, gerando um ciclo virtuoso de desenvolvimento.

O Mapa 4 representa a distribuição geográfica de autores de artigos indexados pelo ISI em 2000. Nele se observa uma forte concentração da produção científica, maior entre as variáveis analisadas. Apenas 12 microrregiões possuem mais de 300 artigos científicos no período entre 1999 e 2001. Como já mencionado, essa concentração está fortemente relacionada à existência de universidades e centros de pesquisa, que são desigualmente distribuídas no espaço.

Até esse ponto, a análise descritiva permite algumas observações. Notase que existe uma hierarquia de concentração espacial em relação às quatro variáveis analisadas, a saber (em ordem decrescente): número de agências, concessão de crédito, número de patentes e produção de artigos científicos. Isso permite inferir, de forma bastante cautelosa, que a produção de patentes, ao se situar no ranking entre artigos científicos e oferta de crédito, teria no primeiro (produção científica) um insumo essencial para a sua produção (talvez até um pré-requisito) e no segundo o elemento que viabiliza a sua produção. Isso explicaria o porquê dos diferenciais de concentração. 
MAPA 4

Distribuição regional de artigos científicos (1999-2001)

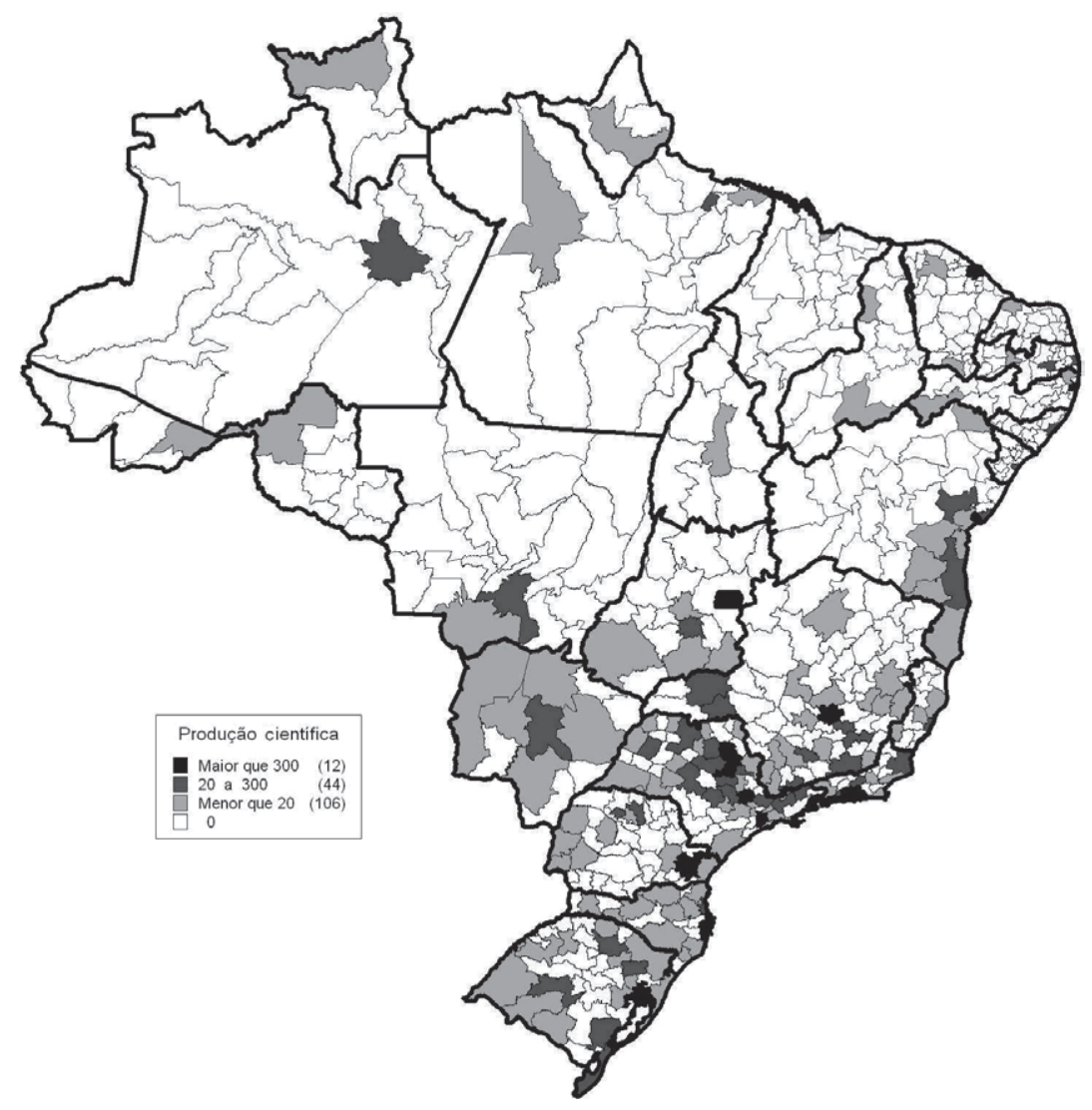

Fonte: LEMTe e Grupo de Economia da Ciência e Tecnologia - CEDEPLAR-UFMG.

\subsection{Metodologia: modelos para variáveis dependentes ordenadas}

Muitos fenômenos sociais são mensurados por variáveis categóricas ordenadas, as quais assumem valores numéricos para denotar a ordem (rank) de um atributo específico. Para o objetivo explícito deste trabalho, a variável patente será o ponto principal de interesse. Entretanto, esses rankings não necessariamente representam as magnitudes reais em uma escala, ou seja, a distância entre duas categorias adjacentes de uma variável ordenada não é necessariamente a mesma entre diferentes segmentos da sua distribuição, 
o que favorece maior flexibilidade ao estudo por não exigir maior rigor na classificacão da variável.

Segundo Oliveira (2004), variáveis ordenadas podem ser vistas como algo entre variáveis nominais por um lado e variáveis contínuas por outro no seguinte sentido: são mais gerais que as contínuas, ao permitir distâncias variantes entre valores adjacentes, mas mais restritas que as nominais, ao conter informação de ordem. Tais variáveis são fundamentalmente categóricas, pois tratam as respostas como ordenadas ao invés de nominais, sendo uma escolha subjetiva aos objetivos do estudo. Às vezes, uma resposta pode ser tratada como uma variável nominal ou ordinal.

Se é esperado obter as diferenças nas respostas e os efeitos de variáveis independentes sobre essas diferenças, os métodos para respostas multinomiais não-ordenadas seriam apropriados. Mas, se o interesse principal é na compreensão de como as variáveis explicativas afetam a dimensão conceitual representada pela variável ordinal, modelos ordenados são apropriados; uma variável dependente ordinal pode também ser tratada como contínua sob um pressuposto específico. Esse fato se encaixa bem no propósito do trabalho: o objetivo é estudar um dos sentidos da relação proposta, vendo como as variáveis relacionadas ao sistema financeiro regionalizado afetam as diferentes ordens da localidades segundo o número de patentes registradas.

\section{Odds e odds ratios}

Tomando como base a apresentação de Greene (2003:719), no modelo logit multinomial, as odds entre as categorias $j$ e 1 para um dado $i$ são

$$
\frac{\mathrm{P}_{\mathrm{ij}}}{\mathrm{P}_{\mathrm{i} 1}}=\mathrm{e}^{\mathrm{x}_{\mathrm{i}}^{\prime} \beta_{\mathrm{j}}} \quad j=2, \ldots, J
$$

A log-odds ou logit é então uma função linear de $x_{i}$ :

$$
\log \left(\frac{\mathrm{P}_{\mathrm{ij}}}{\mathrm{P}_{\mathrm{i} 1}}\right)=\mathrm{x}_{\mathrm{i}}^{\prime} \beta_{\mathrm{j}} \quad j=2, \ldots, J
$$


Dada as J-1 odds de referência, a interpretação dos coeficientes do logit multinomial é direta; um coeficiente positivo para uma variável independente $\left(x_{k}\right)$ implica uma odds crescente de observar uma observação na categoria $j$ ao invés da categoria 1 , na medida em que $x_{k}$ aumenta, mantendo as outras covariáveis constantes; um coeficiente negativo implica que as chances de estar na categoria de referência são mais altas em relação a $j$, na medida em que $x_{k}$ aumenta; no caso de $x_{k}$ ser uma variável dummy, $\beta_{j k}$ é uma log-odds ratio:

$$
\log \left[\frac{\left(\mathrm{P}_{\mathrm{j}} \mid \mathrm{x}_{\mathrm{k}}=1\right) /\left(\mathrm{P}_{1} \mid \mathrm{x}_{\mathrm{k}}=1\right)}{\left(\mathrm{P}_{\mathrm{j}} \mid \mathrm{x}_{\mathrm{k}}=0\right) /\left(\mathrm{P}_{1} \mid \mathrm{x}_{\mathrm{k}}=0\right)}\right]=\beta_{\mathrm{jk}}
$$

Interpretar $\beta_{j k}$ como uma log-odds ratio, quando $x_{k}$ é uma variável contínua, requer que se compare $x_{k}=x_{k}^{0}+1$ e $x_{k}=x_{k}^{0}$, onde $x_{k}^{0}$ é qualquer valor arbitrário de $x_{k}$ :

$$
\log \left[\frac{\left(\mathrm{P}_{\mathrm{j}} \mid \mathrm{x}_{\mathrm{k}}=\mathrm{x}_{\mathrm{k}}^{0}+1\right) /\left(\mathrm{P}_{1} \mid \mathrm{x}_{\mathrm{k}}=\mathrm{x}_{\mathrm{k}}^{0}+1\right)}{\left(\mathrm{P}_{\mathrm{j}} \mid \mathrm{x}_{\mathrm{k}}=\mathrm{x}_{\mathrm{k}}^{0}\right) /\left(\mathrm{P}_{1} \mid \mathrm{x}_{\mathrm{k}}=\mathrm{x}_{\mathrm{k}}^{0}\right)}\right]=\boldsymbol{\beta}_{\mathrm{jk}}
$$

Essas relações se referem ao contraste entre a categoria $j$ e a categoria de referência 1; estas podem ser estendidas para um contraste entre quaisquer duas categorias $j$ e $j$, considerando os coeficientes para essas categorias:

$$
\frac{P_{i j}}{P_{i j}}=e^{x_{i}^{\prime}\left(\beta_{j}-\beta_{j}\right)}
$$

Assim, para qualquer variável explicativa, $x_{k}$, a diferença entre os coeficientes $\left(\boldsymbol{\beta}_{j k}-\boldsymbol{\beta}_{j^{\prime} k}\right)$ determina a direção da mudança nas odds entre as categorias $j$ e $j$; uma diferença positiva indica que, à medida que $x_{k}$ aumenta, há uma maior chance de observar a alternativa $j$ e não $j$; isso é o mesmo quando se 
muda a categoria de referência, tal que é possível verificar a mudança relativa nas odds entre quaisquer duas categorias. Isso significa que, ao se analisar o coeficiente encontrado, por exemplo, para crédito per capita, seu valor indica o quanto é mais (ou menos) provável que se mude a categoria da variável dependente (patentes) relativamente a outro(s) estado(s) categórico(s) inferiores ou superiores. Os resultados indicam a probabilidade de se observar um estado categórico em relação a outro; essa característica nos permite verificar a idéia mais geral de que o grau de presença do sistema financeiro na região altera a probabilidade de registro regional de patentes.

\section{Os modelos probits e logits acumulados}

Segundo Oliveira (2004), denotando a observação $i$ em uma amostra pelo subscrito $i$ e dado que a variável resposta $y_{i}$ assume os valores $1,2, \ldots, J(J \geq 3)$, que correspondem às respostas ordenadas, um modelo de probabilidade geral pode ser escrito em termos de probabilidades acumuladas, $\operatorname{Pr}\left(y_{i} \leq j\right)$, ou probabilidade de que $y$ seja menor ou igual a um valor específico $j$; dessa forma, a probabilidade acumulada tem a interpretação de uma freqüência relativa acumulada de uma variável discreta aleatória.

A probabilidade acumulada para o indivíduo $i$ até o nível de resposta $j$, denotado por $C_{i, j}$ é

$$
C_{i, j}=\operatorname{Pr}\left(y_{i} \leq j\right)=\sum_{k=1}^{j} \operatorname{Pr}\left(y_{i}=k\right), \quad j=1, \ldots, J
$$

Por definição, as probabilidades acumuladas devem somar 1, quando $j=J$, significando que $C_{i, j}=1$ para todos os $i$. Essa restrição implica que somente $J-1$ probabilidades acumuladas (ou funçōes delas) são identificadas de forma única.

Sendo a probabilidade acumulada uma função de um vetor de variáveis independentes $\boldsymbol{x}_{i}$ :

$$
C_{i, j}=F\left(\alpha_{j}+\boldsymbol{x}_{i}^{\prime} \beta\right), \quad j=1, \ldots, J-1 .
$$


Onde $F($.) é uma função de distribuição acumulada adequada (na maioria dos casos é uma distribuição simétrica), o modelo logit ordenado é obtido quando $F($.) segue uma distribuição logística acumulada. Escolher uma distribuição normal padrão acumulada para $F($.) leva ao modelo probit acumulado. Nessa especificação, há $J-1$ parâmetros $a_{j}$, que podem ser pensados como pontos de corte, ou interceptos separados, correspondentes às categorias ordenadas das variáveis dependentes. Definir as probabilidades acumuladas dessa maneira significa que $C_{i, j}>C_{i, j-1}$, tal que $F($.) aumenta $\operatorname{com} j$. Assim, os parâmetros $\mathrm{a}_{j}$ são necessariamente não-decrescentes em $j$.

São possíveis diferentes parametrizações desse modelo básico. Poder-se-ia definir $C_{i, j}=\operatorname{Pr}\left(y_{i}>j\right)$; em uma distribuição simétrica, isso é igual a $1-\operatorname{Pr}\left(y_{i} \leq j\right)$, tal que esse modelo reverte os sinais dos coeficientes da parametrização-padrão baseada em probabilidades acumuladas. As probabilidades condicionais das respostas ordenadas podem ser escritas em termos das probabilidades acumuladas da seguinte forma:

$$
\begin{array}{lll} 
& F\left(\alpha_{1}+\boldsymbol{x}_{i}^{\prime} \boldsymbol{\beta}\right) & j=1 \\
\operatorname{Pr}\left(y_{i}=j \mid \boldsymbol{x}_{i}\right)= & F\left(\alpha_{j}+\boldsymbol{x}_{i}^{\prime} \beta\right)-F\left(\alpha_{j-1}+\boldsymbol{x}_{i}^{\prime} \beta\right) & 1<j \leq J-1 \\
1-F\left(\alpha_{J-1}+\boldsymbol{x}_{i}^{\prime} \beta\right) & j=J
\end{array}
$$

Dessa forma, as probabilidades preditas associadas a uma resposta podem ser obtidas a partir desse modelo.

\section{O modelo logit ordenado}

A definição das probabilidades num modelo logit ordenado segue das definições acima, apenas com uma diferente especificação. A probabilidade acumulada do modelo logit ordenado é escrita como

$$
C_{i, j}=\operatorname{Pr}\left(y_{i} \leq j \mid \boldsymbol{x}_{i}\right)=\left[\exp \left(\alpha_{j}+\boldsymbol{x}_{i}^{\prime} \beta\right)\right] /\left[1-\exp \left(\alpha_{j}+\boldsymbol{x}_{i}^{\prime} \beta\right)\right]
$$


Esse modelo é linear na escala logística; sendo $l_{j}\left(x_{i}\right)$ o logit acumulado de $y \leq j$ versus $y>j$,

$$
l_{j}\left(\boldsymbol{x}_{i}\right)=\log \left[\operatorname{Pr}\left(y_{i} \leq j \mid \boldsymbol{x}_{i}\right) / \operatorname{Pr}\left(y_{i}>j \mid \boldsymbol{x}_{i}\right)\right]=\alpha_{j}+\boldsymbol{x}_{i}^{\prime} \boldsymbol{\beta}
$$

Tem-se assim o modelo de odds proporcionais; dados dois vetores de co-variadas $x_{i 1}$ e $x_{i 2}$, as odds de uma resposta $y_{i} \leq j$ versus $y_{i}>j$ são proporcionalmente maiores ou menores entre as duas situações $x_{i}=x_{1}$ e $x_{i}=x_{2}$. Sendo as odds acumuladas associadas aos valores das co-variadas igual a w $\left(\boldsymbol{x}_{h}\right)$ $(h=1,2)$, é obtida a odds ratio acumulada como

$$
\begin{gathered}
\omega\left(\boldsymbol{x}_{1}\right) / \omega\left(\boldsymbol{x}_{2}\right)=\left[\operatorname{Pr}\left(y_{i} \leq j \mid \boldsymbol{x}_{1}\right) / \operatorname{Pr}\left(y_{i}>j \mid \boldsymbol{x}_{1}\right)\right] /\left[\operatorname{Pr}\left(y_{i} \leq j \mid \boldsymbol{x}_{2}\right) / \operatorname{Pr}\left(y_{i}>j \mid \boldsymbol{x}_{2}\right)\right]= \\
\left.=\left[\exp \left(\boldsymbol{x}_{1} \boldsymbol{\beta}\right)\right] /\left[\exp \left(\boldsymbol{x}_{2}{ }^{\prime} \boldsymbol{\beta}\right)\right]=\exp \left\{\left(\boldsymbol{x}_{1}-\boldsymbol{x}_{2}\right)^{\prime} \boldsymbol{\beta}\right)\right\},
\end{gathered}
$$

que é proporcional às distâncias entre os valores das variáveis explicativas.

\section{Descrição das variáveis e dos resultados}

Conforme explicitado no decorrer do artigo, a relação sistema financeiro e inovação admite uma mútua causalidade derivada tanto do fato de que a inovação gera melhorias no sistema produtivo, crescimento econômico e desenvolvimento do sistema financeiro, como tanto melhorias com relação ao volume e à qualidade do financiamento também afetam o processo inovativo. No exercício que se segue, foi priorizada a relação no sentido do sistema financeiro para a inovação. Os dados de patentes foram cruzados com dados que refletem o aspecto financeiro dos municípios e microrregiôes selecionadas. $\mathrm{O}$ intuito é averiguar em que proporção a presença de um ambiente positivo quanto às variáveis financeiras é capaz de afetar diferentes níveis de registro de patentes e com isso poder inferir sobre a real relação entre essas variáveis. Acredita-se que o caráter probabilístico da metodologia ressalta o aspecto regional acima de tudo; apesar de explorar um dos sentidos para investigar a causalidade entre sistema financeiro-inovação, o objetivo aqui é ressaltar o ambiente local como catalisador do processo como um todo. 
Tomando como base a alta concentração no registro de patentes vislumbrada anteriormente, tal variável será recodificada em três categorias que expressarão o potencial de cada município em servir como base para patentes. A categorização do número de patentes levou em consideração a freqüência com que se distribuíram os registros de patentes por município, numa tentativa de separar os municípios de acordo com o potencial em apresentar inovação. De acordo com a amostra, aproximadamente 60\% dos municípios não possuem nenhuma patente registrada. Esses municípios remontam à categoria intitulada nula $(y=1)$. A próxima categoria $(y=2)$ indica os municípios com um número intermediário de registro de patentes (de 1 a 7 ) e representa 30\% da amostra; esse subgrupo da amostra será representado pela categoria denominada médio. A última categoria $(y=3)$ denominada alta, com freqüência próxima a $10 \%$ da amostra, separa os municípios com maiores valores de patentes.

O modelo foi estimado considerando uma correção para heterocedasticidade, que ajusta os erros-padrão conforme uma matriz de variância e co-variância, cujas entradas são ponderadas pelos resíduos de cada observação da amostra (um estimador robusto). No estimador agrupado (clustered) utilizado neste trabalho, essa ponderação dos resíduos deixa de ser própria a cada observação e passa a ser referente às observações presentes no agrupamento (cluster). Dessa forma, a correção da matriz de co-variância considera que municípios presentes na mesma microrregião apresentam variâncias dos resíduos que devem ser ponderadas por um fator comum, que é designado pelo fato de estarem presentes na mesma microrregião. Esse artifício corrobora o nível de análise microrregional proposto por este trabalho, tornando a ponderação da variância dos erros um fato comum ao grupo e não-individual principalmente quando lidamos com altas proporções de concentração regional das variáveis.

Foram cinco os regressores utilizados. O crédito per capita toma o valor do crédito utilizado na seção 3, vale dizer, valores médios entre janeiro de 1999 e dezembro de 2001 da soma das contas de empréstimos e financiamentos industriais e agroindustriais, e divide-o pela população para cada município da amostra. $\mathrm{O}$ acesso bancário é a proporção de habitantes do município por agência bancária, uma medida relativa de disponibilidade e centralidade do sistema bancário. Valores menores de acesso bancário designam uma maior 
disponibilidade de agências por habitante, o que indiretamente indica uma maior oferta de serviços financeiros. Locais que possuam características de maior centralidade apresentam um maior número de agências bancárias (Crocco et al., 2005; Figueiredo et al., 2006), o que propicia maior diversidade na cadeia de agências presentes no município e maior oferta de serviços diferenciados, entre eles a provisão de crédito.

A variável proporção de depósitos do setor público representa a fração de depósitos à vista referentes às atividades econômicas locais de caráter público em relação ao total de depósitos à vista (do setor público e do setor privado). Essa variável é uma proxy para a presença do setor público no município. Um município com maiores proporções de depósitos à vista públicos apresentam maior primazia em atividades correlacionadas a esse setor, que, na maioria dos casos, se configura como um setor preponderantemente constituído por relaçōes econômicas ligadas a atividades terciárias de provisão de serviços públicos.

A inserção bancária, segundo Cavalcante (2006), representa a conta do balancete municipal intitulada Outros Valores e Bens e é um lançamento do ativo dos bancos que reporta a participação societária transitória das instituições bancárias em atividades regionais, além do valor dos bens móveis e imóveis dos bancos em parcerias locais que lhe sejam de interesse. Se os bancos têm participação em negócios de interesse local, o processo de inovação pode ser favorecido pelo fato de o banco participar dos investimentos da empresa como um parceiro, conduzindo os recursos de forma mais eficiente ou mesmo alavancando processos de produção (inovativos ou não). Em geral pode-se afirmar que o maior conhecimento local dos bancos facilita a ligação entre sistema financeiro, região e inovação. Aumentos dessa conta representam uma maior participação do sistema bancário na economia local, o que impõe a essa variável características diretas de atividade bancária regional.

A última variável explicativa utilizada é uma dummy, que reporta se o município em questão apresentou em 2000 algum artigo publicado em revista científica especializada. $O$ fato de a produção científica estar presente em uma localidade remete à presença de órgãos de pesquisa e desenvolvimento tecnológico que contribuem para atividades inovativas que geram patentes (além disso, as instituiçôes de pesquisa podem obter patentes).

O resultado para o logit ordenado é apresentado na Tabela 3. 
TABELA 3

Resultado da regressão logit ordenada

\begin{tabular}{|c|c|c|c|c|c|c|}
\hline & & & & & № C & bs. $=1.144$ \\
\hline & & & & & Wald $\chi^{2}$ & 5) 452,93 \\
\hline & & & & & Prob. $\gamma$ & $x^{2}=0,0000$ \\
\hline & & & & & Pseudo & $R^{2}=0,2702$ \\
\hline Patentes & Odds ratio & $\begin{array}{l}\text { Erros-padrão } \\
\text { robustos* }\end{array}$ & z & $P>|z|$ & $\begin{array}{r}\text { Inter } \\
\text { confian }\end{array}$ & $\begin{array}{l}\text { valo de } \\
\text { ça a } 95 \%\end{array}$ \\
\hline Crédito per capita & 4,618355 & 0,821724 & 8,6 & 0,000 & 3,258642 & 6,545425 \\
\hline Acesso bancário & 5,509151 & 1,218341 & 7,72 & 0,000 & 3,571434 & 8,498196 \\
\hline $\begin{array}{l}\text { Proporção de depósitos } \\
\text { do setor público }\end{array}$ & 0,389496 & 0,049336 & $-7,44$ & 0,000 & 0,303868 & 0,499253 \\
\hline Inserção bancária & 1,093442 & 0,031699 & 3,08 & 0,002 & 1,033046 & 1,15737 \\
\hline Produção científica & 2,472043 & 0,501794 & 4,46 & 0,000 & 1,660629 & 3,679929 \\
\hline
\end{tabular}

* Erro-padrão ajustado para 432 clusters de microrregiões.

Fonte: elaboração própria a partir dos dados.

De acordo com a estimativa, a variação de $1 \%$ no crédito per capita implica o aumento de 3,6 vezes nas chances de se ter um alto número de registros de patentes em relação aos níveis médios e nulos de registros. Isso significa dizer que as chances de se ter um alto número de patentes em relação aos níveis mais baixos aumenta 3,6 vezes, quando se aumenta o crédito. De acordo com esse resultado, podemos acreditar que a maior disponibilidade de crédito dirigido às firmas e às famílias nos municípios favorece positivamente as chances de se ter um alto registro de patentes.

Com relação ao acesso bancário, a variação de $1 \%$ na variável aumenta 4,5 vezes as chances de se ter um número alto de patentes em relação aos níveis mais baixos de patentes. Esse resultado expressa o fato de uma maior acessibilidade aos bancos afetar positivamente as chances de se ter um alto registro de patentes, levando-nos a acreditar que sistemas bancários de maior 
centralidade, com bases de agências mais consolidadas localmente e maior oferta de serviços financeiros, favorecem as chances de se ter um alto número de patentes em relação às categorias média e nula.

Além disso, é importante salientar que a variável acesso bancário também é utilizada na literatura de economia regional como uma proxy do grau de centralidade de uma determinada localidade. $\mathrm{O}$ conceito de centralidade refere-se a uma maior oferta de serviços mais sofisticados, ou serviços centrais na terminologia utilizada por Christaller (1966). Como mostra Santos et al. (2006), é possível estabelecer uma relação entre o grau de centralidade de uma região e a existência de mediadores de conhecimento (knowledge - intermediaries). Estes últimos podem ser definidos como canais de transferência de conhecimento (conduits of knowledge - transfer). Nas palavras de Santos et al.,

"[...] [canais de transferência de conhecimento] podem ser tanto formais como um serviço de design especializado, centros de pesquisa, firmas de engenharia e consultoria - como informais - ser membro de uma associação industrial, participar de conferências e workshops. A existência desses canais está diretamente associada com o grau de centralidade de uma regiāo especifica, uma vez que esta última é diretamente determinada pela oferta de serviços centrais mais sofisticados e complexos. Em outras palavras, um lugar que possa ofertar tais serviços é um lugar central de hierarquia superior. Nesse sentido, é possivel argumentar que quanto maior a centralidade mais fácil será a emergência de externalidades de conhecimento". (2006:12)

O argumento acima também pode ser aplicado à discussão sobre patentes. De forma semelhante, é possível argumentar que canais de transferência de conhecimento facilitam a existência de patentes, uma vez que permitem a obtenção do conhecimento necessário para a geração destas. Assim pode afirmar-se que quanto maior a centralidade de um lugar maior a possibilidade de ocorrência de registro de patentes. $\mathrm{Na}$ medida em que o acesso bancário possa ser entendido como uma proxy do grau de centralidade de uma região, pode-se então afirmar que os resultados aqui obtidos reforçam essa hipótese. 
Esse mesmo panorama pode ser auferido pelos resultados da variável inserção bancária: o aumento de $1 \%$ na presença ativa dos bancos nos municípios aumenta em $9 \%$ as chances de se ter um alto número de registros de patentes em relação aos níveis medianos e nulos. Maior inserção bancária afeta positivamente as chances de se ter um alto número de registros de patentes, pois bancos que atuam localmente como parceiros das firmas tendem a melhorar a capacidade dos investimentos das firmas, diminuindo não só custos de transação como também custos de informação intralocal, propiciando um ambiente favorável ao desenvolvimento da tecnologia.

No entanto, deve ser observado que o resultado obtido por essa variável (9\%) foi baixo quando comparado aos demais resultados (crédito per capita: 360\%; acesso bancário: 450\%; e produção científica: 170\%). Isso deve ser analisado à luz da estrutura bancária brasileira. Como salientado anteriormente, a interação entre bancos e empresas característica do bank system possibilita uma maior participação do sistema bancário na condução das empresas, superando as dificuldades inerentes à assimetria de informação. Isso possibilitaria a emergência de relações mais estáveis e duradouras capazes de gerar o chamado patient money, essencial tanto para o desenvolvimento de atividades quanto para o desenvolvimento de tecnologia (Singh \& Weisse, 1998). No entanto, o resultado mostra que no caso brasileiro a participação de bancos em empresas não pode ser considerado como uma estratégia de desenvolvimento bancário, mas sim o resultado de aquisição de colaterais. Essa interpretação explicaria o porquê da variável inserção bancária, apesar de positiva, ter uma menor capacidade de afetar as chances de se ter um alto número de patentes no município em relação aos níveis inferiores.

A proxy para presença do setor público no município determina que o aumento de $1 \%$ nesse fator faz com que se reduzam em $40 \%$ as chances de se ter um alto número de patentes registradas. Esse resultado é aparentemente contraditório com parte significativa da literatura sobre tecnologia, que mostra o setor público como fundamental para o desenvolvimento de inovações, dada a sua capacidade de enfrentar as incertezas e o lag temporal característico dessa atividade. No entanto, deve ser ressaltado que o resultado observado decorre da variável que está sendo analisada. Uma maior presença de órgãos públicos - medida pela relação entre depósitos à vista do setor 
público sobre o total de depósitos - afeta negativamente as chances de se ter um número alto de patentes, provavelmente porque municípios cujas atividades econômicas se caracterizam por uma predominância de caracteres setoriais públicos tendem a ser municípios de baixo dinamismo econômico. Este seria o caso, por exemplo, de municípios pequenos, com setor industrial irrelevante. Uma vez que a variável de patente pressupóe a existência de possibilidade de aplicação comercial da inovação (pelo menos do ponto de vista do patenteador), o baixo dinamismo econômico, característico desse tipo de cidade, reduziria a probabilidade de ocorrência de patentes.

Quanto à dummy de produção científica, pode ser posto que para municípios com produção científica as chances de apresentarem um alto número de registro de patentes versus os valores medianos e nulos são aproximadamente 1,5 vezes maiores do que municípios sem produção científica, mantido todo o restante constante. A proximidade de centros difusores de tecnologia favorece o estabelecimento de redes de relacionamento que são capazes de aumentar as chances de alcançar um alto número de registros de patentes.

\section{Conclusão}

A partir de uma formulação geral que sugere a existência de mútua causalidade entre as dimensões monetário-financeira e industrial-inovativa, este artigo realizou um exercício estatístico para testar um dos sentidos dessa causalidade, o sentido indica a influência positiva das finanças sobre a inovação. Para os objetivos deste artigo, os resultados desse exercício enriquecem as discussões e justificam a continuidade dessa linha de pesquisa, especialmente buscando investigar o outro sentido da mútua causalidade.

É importante indicar a consciência das limitações dos dados aqui analisados. A dimensão financeira foi limitada às variáveis bancárias. Por mais importantes que sejam, elas deixam de fora variáveis como o mercado de capitais (bolsas de valores e suas repercussōes, limitadas ou não, sobre o esquema de financiamento). É verdade que as variáveis relativas a mercado de capitais não podem ser discutidas em âmbito regional de uma forma direta (tema deste artigo). No entanto, a tentativa de incorporar esse tópico, possivelmente através das firmas e sua participação no mercado de capitais, é parte 
da nossa agenda de pesquisa. $\mathrm{Na}$ seção 1 , ao buscar localizar a posição do país no cenário internacional, as variáveis relativas aos mercados de capitais haviam sido incluídas.

Para qualificar a análise dos dados, é também importante destacar que a conexão aqui sugerida entre sistema bancário e inovação certamente passa por inúmeros canais intermediários, que merecem investigação também detalhada. Os dados disponibilizados pela PINTEC-IBGE, por exemplo, indicam que $90 \%$ das atividades de $\mathrm{P} \& \mathrm{D}$ realizadas no país são financiadas por recursos próprios (Henriques, 2007). Esses dados sugerem a necessidade de maiores investigaçõos sobre a articulação entre a estrutura interna das empresas e a disponibilidade de crédito, pois a influência de melhores condições de oferta de crédito pode operar sobre a capacidade inovativa das empresas, ao permitir uma maior mobilização interna de recursos para atividades carregadas de risco como a P\&D. Mesmo que a firma financie a inovação com recursos próprios, outras necessidades de investimento ficariam desfavorecidas, o que exigiria captação de recursos externos para tais fins (como, por exemplo, capital de giro específico ou não para o processo inovativo). O financiamento externo tem caráter cíclico, o que significa que em fases de expansão, mesmo com expansão de recursos internos, ainda existe alta da procura por crédito.

Essas qualificações contextualizam o objetivo específico deste artigo: explorar as possíveis conexões entre variáveis financeiras e produção de patentes. Embora esta seja uma área pouco explorada, tanto teoricamente quanto empiricamente, procurou-se contribuir para essa literatura através de uma análise mais desagregada (microrregião e municípios). Os resultados das análises tanto descritiva quanto do modelo logit ordenado permitem argumentar que existe uma importante relação entre produção científica, concessão de crédito e centralidade e a produção de patentes.

Em primeiro lugar, foi demonstrado na análise descritiva que existe uma forte concentração espacial das variáveis crédito, patentes e artigos científicos, e o grau de concentração é maior para a última variável e menor para a primeira. Em segundo lugar, a análise do modelo logit ordenado mostrou que variaçōes positivas no crédito, no acesso bancário (proxy de centralidade) e na produção científica aumentam as chances de uma localidade ter um maior número de patentes registradas. Esses dois resultados, tomados em conjunto, permitem 
atentar para o fato de que a produção científica pode ser considerada como um pré-requisito para a produção de patentes, mas, no entanto, a concessão de crédito na localidade se torna o elemento viabilizador desta. Isso pode ser inferido pelos valores apresentados na análise do logit ordenado, em que fica claro que a variação positiva da variável crédito é aquela que mais aumenta a possibilidade de um aumento na produção de patentes. Isso poderia dar-se através do crédito direcionado diretamente para a produção de patentes, ou através do seu impacto positivo sobre o nível de atividade econômica, fato este impulsionador da produção de patentes.

Permeando toda essa discussão, ficou também evidente o papel central desempenhado pela centralidade urbana, que afetaria tanto a produção científica, quanto a concessão de crédito.

Deve-se ressaltar o caráter exploratório deste trabalho e a necessidade da continuidade da investigação do tema em trabalhos futuros. $\mathrm{O}$ intuito principal deste trabalho é abrir o debate sobre o tema e para isso traz algumas informações importantes. Por outro lado, seu aspecto exploratório exige cuidados na interpretação dos resultados. A escolha pela representação de um lado da causalidade, mais precisamente do sistema financeiro para a inovação, exige que o outro sentido também seja estudado. Uma melhor especificação da relação também invoca mais pesquisa; neste trabalho deu-se prioridade apenas a variáveis do sistema financeiro para explicar a inovação em termos regionais. Outro trabalho seqüencial seria controlar tal relação com outras variáveis que afetam tanto o sistema financeiro, quanto a inovação (como o tamanho de empresas, o setor de atividade, a proximidade de centros de pesquisa etc.) Acima de tudo, o importante é que os resultados até aqui obtidos representam um estímulo para um maior aprofundamento desta agenda de pesquisa.

Este artigo, enfim, talvez contribua para indicar como é complexo o importante exercício teórico e empírico para aperfeiçoar a articulação entre sistemas de inovação e sistemas financeiros. Mas, ao mesmo tempo, demonstra que há diversos caminhos por meio dos quais essa integração pode ser buscada. E esses diversos caminhos de forma alguma se excluem. 


\section{Referências bibliográficas}

Albuquerque, E.M. Causa e efeito: contribuiçôes de Marx para investigaçôes sobre finanças e inovação, Belo Horizonte: CEDEPLAR-UFMG, (TD 326), 2008.

Arestis, P.; Chortareas, G.; Desli, E. "Financial development and productive efficiency in OECD countries: an explanatory analysis", The Manchester School of Economic and Social Research, v.74, n.4, 2006.

Arestis, P.; Demetriades, P. "Financial development and economic growth: assessing the evidence", Economic Journal, v.107, n.442, 1997.

. "Finance and growth: is Schumpeter right?", Análise Econômica, v.16, n.30, p.5-21, 1998.

Arestis, P.; Demetriades, P.; Fattouh, B. "Financial policies and the average productivity of capital: evidence from developed and developing economies", Eastern Economic Journal, v.29, n.2, 2003.

Arestis, P.; Nissanke, M.; Stein, H. "Finance and development: institutional and policy alternatives to financial liberalisation theory", Eastern Economic Journal, v.31, n.2, 2005.

Campelo, P.G. "Investimento inovativo: a questão do financiamento", Dissertação de Mestrado, Niterói, UFF, 2000.

Carney, M.; Gedajlovic, E. "East Asian Financial Systems and the transition from investment-driven to innovation-driven economic development", International Journal o Innovation Management, v.4, n.3, p.253-276, 2001.

Carvalho, F.C. "Keynes's concept of finance and funding, and the structure of the financial system", Texto para Discussão, Rio de Janeiro: UFRJ-IEI, n.344, 1995.

Cavalcante, A. "Financiamento local e desenvolvimento: um estudo sobre arranjos produtivos", Dissertação de Mestrado em Economia, Belo Horizonte, CEDEPLAR - Centro de Desenvolvimento e Planejamento Regional, Universidade Federal de Minas Gerais, 2006.

Chesnais, F. La mondialisation du capital, Paris: Syros, 1994. . La mondialisation financière: genèse, coût et enjeux, Paris: Syros, 1996. 
Chesnais, F. (org.) La finance mondialisée: racines sociales et politiques, configuration, conséquences, Paris: La Découverte, 2004.

Christaller, W. Central places in southern Germany, Englewood Cliffs: Prentice-Hall, 1966.

Christensen, J.L. "The role of finance in national systems of innovation", in Lundvall, B.-A. (ed.), National systems of innovation: towards a theory of innovation and interactive learning, Londres: Pinter, p.146-168, 1992.

Corder, S.; Salles-Filho, S. "Aspectos conceptuais do financiamento à inovação", Revista Brasileira de Inovação, v.5, n.1, p.33-76, 2006.

Crocco, M.; Cavalcante, A.; Barra, C. "The behavior of liquidity preference of banks and public and regional development: the case of Brazil", Journal of Post Keynesian Economics, v.28, n.2, p.217-240, dez.-jan., 2005.

Erber, F.E. "O sistema de inovação em uma economia monetária - Uma agenda de pesquisas", in Cassiolato, J.E.; Lastres, H.M., Gobalização e inovação localizada, Brasília: IBICT-MCT, 1999.

Figueiredo, A.; Menezes, M.; Crocco, M. "Estudo exploratório sobre o padrão locacional dos bancos: análise multivariada para o estado de Minas Gerais", in Anais do XII Seminário sobre a Economia Mineira, Diamantina, 2006.

Freeman, C. Technologicy policy and economic performance: lessosns from Japan, Londres: Pinter, 1987.

Gerschenkron, A. Economic backwardness in historical perspective, Cambridge: Harvard University, 1962.

Goodcare, A.; Tonks, I. "Finance and technological change", in Stoneman, P. (ed.), Handbook of the economics of innovation an technological change, Cambridge (MA): Basil Blackwell, 1995.

Greene, W. Econometric analysis, 5ํㅗㄹ ed., Upper Saddle River (NJ): Prentice Hall, 2003.

Harrison, R; Mason, C. "The role of the public sctor in the development of a regional venture capital industry", Venture Capital, v.2, n.4, p.243-253, 2000.

Henriques, T.R. "O papel do sistema financeiro brasileiro no sistema nacional de inovação: uma introdução à discussão a partir dos dados da PINTEC 2003", Monografia de Conclusão de Curso, Belo Horizonte, FACE-UFMG, 2007. 
Herskovic, B. "Efeitos recíprocos entre crédito e inovação", Monografia de Conclusão de Curso, Belo Horizonte, FACE - UFMG, 2007.

King, R.; Levine, R. "Finance and growth: Schumpeter might be right", Quaterly Journal of Economics, CVIII, p.717-737, 1993.

Kregel, J. "Capital flows: globalization of production and financing development", UNCTAD Review, p.23-38, 1994.

Lamoreaux, N.; Levenstein, M.; Sokoloff, K. "Financing invention during the second industrial revolution: Cleveland, Ohio 1870-1920", Working Paper 10.923, NBER Working Paper Series, 2004.

Levine, R. "Financial development and economic growth: views and agenda", Journal of Economic Literature, v.XXXV, p.688-726, 1997.

Maddala, G.S. Limited dependent and qualitative variables in econometrics, Cambridge: Cambridge University, cap.2, 1983.

Marx, K. (1857-1858) Grundrisse. Londres: Penguin Books, 1973.

. (1867) Capital: a critique of political economy, Londres: Penguin Books, v.I, 1976.

. (1894) Capital: a critique of political economy, Londres: Penguin Books, v.III, 1981.

Megna, P.; Klock, M. “The impact of intangible capital on Tobin's q in the semiconductor industry”, American Economic Review, 83 (20), p.265-320, 1993.

Mello, L.M. "Financiamento da inovação industrial", Tese de Doutorado, Rio de Janeiro, IE-UFRJ, 1994.

Miller, M.H. "Financial markets and economic growth", Journal of Applied Corporate Finance, 11, p.11-14, 1998.

Minsky, H.P. Stabilizing an unstable economy, New Haven: Yale University Press, 1986.

Murray, G. "A policy response to regional disparitiesin the supply of risk capital to new technology - Based firm in European Union", Regional Studies, v.32, n.5, p.405-419, 1998.

Oliveira, A.M.H. "Modelos de resposta binária: algumas notas", CEDEPLAR, UFMG, mimeo, jul., 2004. 
O'Sullivan, M. "Finance and innovation", in Fagerberg, J.; Mowery, D.; Nelson, R., Oxford handbook on innovation, Oxford: Oxford University Press, 2004.

"Funding new industries: a historical perspective on the financing role of the US stock market in the $20^{\text {th }}$ century”, 2005 (working in progress paper apresentado ao Barcelona Economics of Innovation Workshop - CREI-CREA, mar., 2006).

Perez, C. Technological revolutions and financial capital, Cheltenhm: Edward Elgar, 2002.

Prowse, S.D. "Corporate finance in international perspective: legal and regulatory influences on financial system development", Federal Reserve Bank of Dallas Economic Review, third quarter, 2-16, 1996.

Santos, F.; Crocco, M.; Jayme Jr., F.G. "Knowledge externalities and growth in peripheral regions: introductory notes”, Texto para Discussão, CEDEPLARUFMG, n.278, 2006 (também publicado em Arestis, P.; Baddeley, M.; McCombie, J. (eds.), Economic growth - Edward Elgar, 2006).

Scherer, F.; Ross, D. Industrial market structure and economic performance, Boston: Houghton Mifflin, 1990.

Schumpeter, J. (1911) A teoria do desenvolvimento econômico, São Paulo: Nova Cultural, 1985.

(1942) Capitalismo, socialismo e democracia, Rio de Janeiro: Zahar Editores, 1984 .

Singh, A.; Weisse. B. "Emerging stock markets, portfolio capital flows and long-term economic growth: micro and macroeconomic perspectives", World Development, 26 (4), p.607-622, 1998.

Smith, A. (1776) A riqueza das nações: investigação sobre sua natureza e suas causas, trad. port., São Paulo: Abril Cultural, 1983.

Studart, R. Investment finance in economic development, Londres, Nova York: Routledge, 1995.

Teece, D.J. "Capturing value form knowledge assets: the new economy, markets for know-how and intangible assets", California Management Review, 40 (3), p.55-79, 1998. 
UNCTAD. "The growth of domestic capital markets, particularly in developing countries, and its relationship with foreign portfolio investment", United Nations Commission on Trade and Development Secretariat, <http://www. unctad.org/en/special/c2em4d2.html>, 1998.

Wooldridge, J.M. Econometric analysis of cross section and panel data, Cambridge (MA): MIT Press, cap.15, 2002.

Zysman, J. Governments, markets, and growth: financial systems and the politics of industrial chance, Ithaca: Cornell University, 1983.

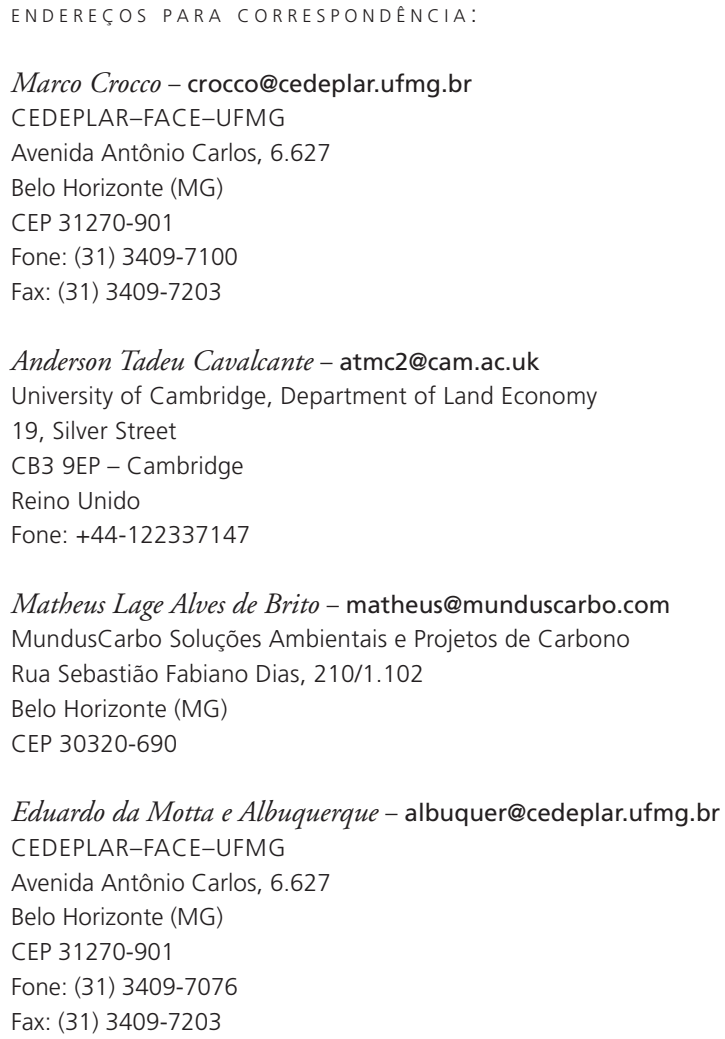

